\title{
Paralelo qualitativo entre grupos focais presenciais e virtuais: Limitações e potencialidades vistas a partir do Iramuteq
}

\section{Angela Canuto ${ }^{1}$, Lucas Monteiro', Beatriz Braga', Rodrigo de Melo', Julia de Sá1, Lorenna Monteiro² e Cecíla Barbosa ${ }^{1}$}

${ }^{1}$ Faculdade de Medicina, Universidade Federal de Alagoas - UFAL, Brasil | angela_canuto@uol.com.br; lucas.monteiro@famed.ufal.br; beatriz.braga@famed.ufal.br; ropparanhos@gmail.com; julia.duartesa@outlook.com; cecilia.barbosa@famed.ufal.br. | https://orcid.org/0000-0002-5517-7837; https://orcid.org/0000-0002-7207-6501; https://orcid.org/0000-0002-7958-2714; https://orcid.org/0000-0003-1751-4748; http://orcid.org/0000-0002-5913-3508; https://orcid.org/0000-0002-7120-1374

2 Programa de pós-graduação em Sociedade, Tecnologias e Políticas Públicas - SOTEPP, Brasil | falecomalore@gmail.com | http://orcid.org/0000-0003-2072-7154

Resumo: Introdução Grupos Focais (GF) são ferramentas essenciais, na pesquisa qualitativa, para a coleta de dados subjetivos, como opiniões e experiências sobre determinados temas, podendo ocorrer tanto presencial quanto virtualmente. Em tempos de impossibilidade de realização das discussões presenciais, sua realização online é uma alternativa valiosa, porém ainda recente. Dessa forma, este artigo busca a comparação entre as duas vertentes metodológicas, observando por diferenças relevantes entre ambas. Objetivos: Analisar os pontos positivos e limitações de cada vertente de grupo focal, através da comparação entre os resultados de transcrições processadas no software Iramuteq e entre a experiência empírica dos autores com as modalidades de grupos focais. Métodos: Realização de grupos focais presenciais e virtuais, pelo Google Meet, com posterior análise e comparação de dados coletados de Grupos Focais realizados presencial e virtualmente, a partir de extensa revisão bibliográfica do tema, corpus textuais de oito grupos focais realizados em anos distintos da graduação, e nuvens de palavras, análises lexicográficas e de similitude geradas pelo software IRAMUTEQ, assim como comparação das experiências dos pesquisadores observadores com as duas vertentes de metodologia. Resultados: Através da análise lexicográfica dos grupos focais, bem como das ferramentas gráficas, podese observar uma mudança positiva em relação aos grupos focais do ano 02 , em relação ao ano 01, em três dos quatro GF estudados. Discussão: É possível coletar dados sensíveis de diversas temáticas por ambas as modalidades de GF, seja virtual ou presencialmente, respeitando as técnicas e características da ferramenta de discussão. Existem grupos que naturalmente se sentem mais à vontade respondendo questionários pessoalmente, enquanto outros grupos evoluem melhor e mais confortavelmente através de discussões online. Conclusões: $O$ uso de Grupos Focais virtuais é bastante prático para pesquisadores e participantes, desde que seja da forma mais verossímil possível com um GF presencial.

Palavras-chave: Pesquisa Qualitativa. Grupos Focais. Análise de Dados, Iramuteq.

Qualitative Parallels between Online and in-person Focus Groups: Strengths and Weaknesses Seen through Iramuteq

Abstract: Introduction Focus Groups are essential tools in qualitative research, due to its capacity to acknowledge different points of view and analyze them in one cohesive methodological process. It can occur either in-person or online, with strengths in both methods. This project focus on the comparison between two modalities of focus group research, noting relevant differences between the two. Goals: To analyze each method's strengths and weaknesses through the author's empiric experiences with both modalities of focus groups and the data processed in Iramuteq. Methods: In-person and online Focus Groups, the latter accomplished through Google Meet, with posterior analysis and comparison of collected data in the eight accomplished Focus Groups through Iramuteq's tools: Word Cloud Similitude analysis and lexicographic text analysis. Results The lexicographic text analysis, alongside both Word Cloud and Similitude Analysis, showed a positive change in participant engagement and discussion length, except for one of the feminine focus groups. Both word frequency and word correlation grew in the second year of the other three focus groups, when comparing with the first year. Focus group recording became easier through online discussions due to the file being already in a format ready to use and being a video file showing each person in the discussion at the same time. Discussion: From the data gathered it can be implied that the focus groups became more comfortable with the online method of discussion, when compared to the in-person version applied in the year before. 
Conclusions. Online focus groups are more practical to researches and participants alike, however, it is necessary to focus on the engagement of the group in a determined method before choosing the more practical way to apply it.

Keywords: Qualitative Research. Focal Groups. Data, Iramuteq

\section{Introdução}

Pode-se considerar os Grupos Focais (GF) como importantes dispositivos dentro da pesquisa qualitativa, principalmente quando o pesquisador objetiva coletar informações sensíveis sobre um determinado tema. Esta coleta, que se dá através de discussões e debates entre os participantes, foi sendo adaptada ao longo da revolução tecnológica pela qual o mundo passou, o que tornou possível a realização dos GF não só na forma presencial, como também de forma remota, em reuniões online (Dall'Agnol et al, 2012).

É importante considerar, na utilização dos GF em coleta de dados, as características que tornam a discussão empática e fluida. Segundo Martínez e González (2015), devemos dar a devida importância ao número e tamanho dos grupos e à heterogeneidade dos participantes, bem como lembrar do papel dos pesquisadores e observadores envolvidos para assim coletar e conhecer vivências, percepções, opiniões e comentários dos participantes.

A técnica dos Grupos Focais amplamente utilizada em pesquisas qualitativas, é uma ferramenta interessante para observar os movimentos grupais fundamentais que constituem as representações sociais. Nesse sentido, durante o decorrer da reunião, é possível perceber e visualizar a intersubjetividade, a relação entre os diferentes conhecimentos, as interações entre as pessoas e o mundo social (Nóbrega et al, 2016).

Dessa forma, Prates (2015) descreve que um GF propicia um ambiente condutor e estimulante para troca de experiências, percepções e sentimentos, tornando possível um pensar coletivo. Além disso, permite aprofundar e problematizar os significados dos temas a serem trabalhados na ocasião, abrindo um leque de possibilidades para o desenvolvimento da pesquisa e dos resultados a serem buscados.

Paralelamente, Gatti (2015) constata que, apesar da pouca quantidade de estudos e pesquisas envolvendo a técnica, há um amplo campo de trabalho, das mais diversas áreas do conhecimento, para os profissionais explorarem utilizando-se dos GF dentro do universo da pesquisa qualitativa. Nesse sentido, a diversidade de temas dos grupos presentes na literatura científica internacional, como os investigativos e os terapêuticos, tornam os grupos como instrumentos profícuos na promoção de saúde e bem-estar do grupo participante.

Em estudos comparativos entre GF presenciais e online, é possível notar que não há diferenças significativas entre eles. Particularidades de cada modalidade foram observadas, como diferenças na contagem de palavras, e a abordagem mais aprofundada de questões pessoais no formato online, mas constatou grande semelhança em relação ao conteúdo, o que permitiu coletar dados em tópicos sensíveis tanto presencial como em discussão online (Woodyatt, 2016).

A partir disso, o presente estudo também visa comparar as técnicas e resultados dos grupos focais presenciais e virtuais, entender as semelhanças e diferenças, e a partir dos resultados, observar limitações e potencialidades das modalidades, a fim de estabelecer, na literatura relacionada a estudos em pesquisa qualitativa, um comparativo da experiência dos pesquisadores e participantes dos grupos focais.

É mister salientar que foi optado pela modalidade virtual dos grupos focais em razão da pandemia do novo Coronavírus (SARS-CoV-2), deflagrada em meados de 2020, que impossibilitou a realização das discussões em formato presencial. Diante disso, foi possível comparar os dois métodos de discussão e avaliar os pontos positivos e negativos relacionados a cada um deles, além de questionar os participantes acerca de temas específicos relacionados ao período de isolamento social associado à pandemia. 


\section{Objetivos}

\subsection{Objetivo Geral:}

Analisar os pontos positivos e negativos da realização de GF na modalidade online e presencial à luz das experiências dos autores e da análise dos corpus gerados no software IRAMUTEQ em ambos.

\subsection{Objetivos Específicos:}

- Avaliar a logística de aplicação dos dois tipos de GF;

- Comparar seus pontos positivos e limitações;

- Comparar a qualidade dos resultados obtidos nos dois tipos de GF através da análise das transcrições processadas no IRAMUTEQ;

- Evidenciar a experiência prática dos autores com as modalidades de GF.

\section{Metodologia}

O presente estudo busca promover uma análise das modalidades presencial e virtual de Grupos Focais (GF) utilizadas pelos pesquisadores durante as duas primeiras etapas do projeto "Humanização Dos Alunos De Medicina: Uma Análise Gradativa Dos Níveis De Empatia No Curso De Medicina De Uma Universidade Pública Em Analogia Ao Artigo Americano 'The Devil Is In The Third Year: A Longitudinal Study Of Erosion Of Empathy In Medical School'", realizadas com o mesmo grupo de participantes durante os anos de 2019 e 2020 e processadas através do Software IRAMUTEQ (Versão 0.7 alfa 2), no sistema operacional Windows 10.

Nesse sentido, a primeira etapa consistiu em uma intensa revisão bibliográfica entre os anos 2009 a 2019 nas bases de dados Scielo, Biblioteca Nacional em Saúde e PubMed na busca de artigos de relevância em português e inglês, com um enfoque maior nos trabalhos com data de publicação a partir de 2015. Foram utilizados os descritores "Pesquisa Qualitativa", "Grupo Focal", "IRAMUTEQ", "Análise Comparativa", "Análise Lexical" e a operação Booleana AND destes para elucidação dos pontos positivos e limitações de cada programa.

Além disso, foi realizada uma leitura integral do manual do IRAMUTEQ, disponível no site do programa, para investigação das funções que melhor representam a comparação entre os corpus textual. As seguintes ferramentas do IRAMUTEQ foram utilizadas: frequência dos 20 termos mais frequentes corpus; somatório das frequências dos 20 termos mais frequentes do corpus, Nuvem de Palavra e Análise de Similitude.

Os GF foram compostos de 8 participantes, tanto em 2019 quanto em 2020, alocados por gênero e a discussão foi guiada por perguntas semi-estruturadas dirigidas por um mediador, a fim de sensibilizar os participantes e permitir a livre expressão. $O$ roteiro proposto teve objetivo de proporcionar ao entrevistador melhor entendimento e captação da perspectiva dos entrevistados. Os questionamentos foram divididos em categorias, baseadas nas Diretrizes Curriculares Nacionais do Curso de Graduação em Medicina de 2014, que consistem em: Qualidade das interações interpessoais na relação médicopaciente; Comunicação durante a consulta e compreensão do paciente; Percepção do paciente sobre prognóstico e tratamento; Satisfação do paciente; Respeito e ética médicopaciente. Os Grupos Focais Virtuais foram realizados através da plataforma "Google Meet", e todas as discussões foram iniciadas após assinatura do TCLE. Ao fim de cada grupo focal, um arquivo de vídeo foi salvo para que as transcrições pudessem ser realizadas.

A realização de transcrições digitais para futuro processamento no IRAMUTEQ foi feita manualmente usando o software Apache OpenOffice 4.1.7, recomendado no manual de instruções do IRAMUTEQ, para que não haja corrupção de dados durante a análise pelo software. 
Essa análise empírica das duas modalidades de Grupo Focal, aplicados na mesma pesquisa longitudinal dos autores, leva em consideração os seguintes fatores: praticidade, grau de interação dos participantes e benefício para a análise qualitativa, permitindo uma comparação dos critérios logísticos de seu uso ao observar, na prática, as vantagens e desvantagens de cada opção metodológica para artigos da vertente qualitativa.

De acordo com a Resolução 510/16 do Conselho Nacional de Saúde, foi aplicado o Termo de Consentimento Livre e Esclarecido a todos os participantes. Os dados coletados serão mantidos sob sigilo com os pesquisadores e a pesquisa foi submetida à Plataforma Brasil com CAAE: 09805119.7.0000.5013.

\section{Resultados}

A pesquisa "Humanização Dos Alunos De Medicina: Uma Análise Gradativa Dos Níveis De Empatia No Curso De Medicina De Uma Universidade Pública Em Analogia Ao Artigo Americano 'The Devil Is In The Third Year: A Longitudinal Study Of Erosion Of Empathy In Medical School"' é um projeto de pesquisa híbrida que teve sua etapa qualitativa iniciada na modalidade presencial durante 0 ano de 2019, período em que foram realizados grupos focais também presenciais com os estudantes de medicina que no momento cursavam o $1^{\circ}$ e $2^{\circ}$ Períodos da graduação em Medicina. Esses dados são denominados como "Ano 01", pois são referentes ao $1^{\circ}$ ano da graduação de medicina dessas duas turmas.

Durante o ano de 2020, por causa do cenário pandêmico internacional e início das aulas de Ensino a Distância $(\mathrm{EaD})$ na Universidade Federal de Alagoas, onde a pesquisa é conduzida, a metodologia do projeto foi transformada em virtual, sendo agora proporcionada através de grupos focais online, porém mantendo as mesmas turmas de estudantes de medicina do Ano 01 . Os alunos durante 2020 atingiram o $3^{\circ}$ e $4^{\circ}$ período da graduação, de modo que os dados referentes ao ano de 2020 são denominados "Ano 02", por se tratar do $2^{\circ}$ ano de graduação dessas turmas de médicos em formação.

Os Grupos Focais presenciais ocorreram dentro das instalações da Faculdade de Medicina da Universidade Federal de Alagoas e foram gravadas através dos gravadores internos dos celulares dos gravadores, em 2019. Já durante 2020, os Grupos Focais Virtuais, realizados através da plataforma Google Meet, foram gravados através da ferramenta interna do Google Meet de realizar gravação da chamada, gerando um arquivo de vídeo com todos os participantes presentes, capturando as câmeras durante o período em que estiveram ligadas.

Os aspectos quantitativos desse projeto, a aplicação do questionário JSPE-S de Hojat, permaneceram os mesmos durante todo o processo, sendo conduzidos virtualmente tanto em 2019 quanto em 2020. A metodologia de análise das transcrições de grupo focal foi idêntica em ambos os anos, através do processamento dos arquivos ".txt" no IRAMUTEQ para obtenção das Frequências dos Termos, Nuvens de Palavras e Análises de Similitude dos quatro corpus textuais gerados em cada ano. A seguir, além de descrever em brevidade o Software utilizado e suas ferramentas internas, obtém-se a comparação entre os grupos focais da modalidade presencial e os grupos focais da modalidade virtual.

As comparações a seguir serão feitas primordialmente entre as Análises Lexicográficas Clássicas, seguidas por comparações adjuntas que servem principalmente para demonstrar de maneira gráfica os resultados obtidos e o uso das ferramentas do IRAMUTEQ nesses dois anos de pesquisa, além de facilitar a visualização do fluxo de discussão de uma das turmas estudadas. Ainda que todas as ferramentas sejam vitais para o seguimento desta pesquisa, as análises aqui apresentadas são suficientes para promover a discussão entre os GF presenciais e virtuais. 


\subsection{O Iramuteq}

O IRAMUTEQ (Interface de R pour les Analyses Multidimensionnelles de Textes et de Questionnaires) é um Software de Análise de Dados Qualitativos Assistidos por Computador (CAQDAS) que foi desenvolvido pelo francês Pierre Ratinaud em 2009, sendo uma extensão do Software estatístico $\mathrm{R}$ e construído utilizando a linguagem de programação Python. O IRAMUTEQ, ainda que francês, apresenta, durante a submissão do corpus, configurações para codificação binária de comprimento variável em todas as línguas, representada na "uft-8 All Languages", além de seleção da língua a ser analisada neste arquivo específico.

Este Software apresenta cinco tipos de análise textual diferentes, sendo elas: Análise Lexográfica Clássica; Especificidade e Análise Fatorial de Correspondência; Classificação Hierárquica Descendente (CHD); Análise de Similitude; e Nuvem de Palavra. O foco deste artigo é na Análise Lexográfica Clássica, Nuvem de Palavra e Análise de Similitude, dado que são as metodologias que mais satisfizeram as expectativas dos pesquisadores durante o desenvolvimento do projeto (Souza, 2018).

\subsection{Análise Lexográfica Clássica}

A Análise Lexográfica Clássica, também conhecida como Análise Estatística Textual, identifica e reforma as unidades textuais, transformando os textos em segmentos textuais, identificando a quantidade de palavras, frequência média e hapax (palavras com frequência igual a 1), além de pesquisar os vocabulários e reduzir palavras com base em suas raízes (formas reduzidas). Outras funções incluem criação de formas reduzidas e identificação das formas ativas e suplementares, definição que ocorre antes do processamento textual nas propriedades da análise (Loubère e Ratinaud, 2014). Foram estudados os 20 termos mais frequentes de cada transcrição, com obtenção do somatório das frequências e análise dos termos mais frequentes.

As Tabelas 1 e 2 são referentes aos alunos que cursaram o $1^{\circ}$ Período da Graduação em medicina durante 2019 e o $3^{\circ}$ Período em 2020, sendo cada tabela representativa do sexo do GF conduzido pelos autores. Em relação ao grupo masculino, somatório das ocorrências dos 20 termos mais frequentes do Ano 01 foi 169, enquanto no Ano 02 o somatório dessas frequências foi 375 . O número de frequências torna-se mais proporcional neste grupo a partir do terceiro termo da análise lexicográfica do ano 02 (coisa, com 23 ocorrências), sendo comparável ao primeiro termo da análise lexicográfica do ano 01 (empatia, com 27 ocorrências).

Tabela 1. Frequência dos termos mais mencionados pelo Grupo Focal Masculino do $1^{\circ}$ Período em 2019 e do $3^{\circ}$ Período da mesma turma em 2020

\begin{tabular}{cccc}
\hline Termo no Ano 01 & Frequência & Termo no Ano 02 & Frequência \\
\hline empatia & 27 & achar & 57 \\
achar & 20 & empatia & 42 \\
médico & 14 & coisa & 23 \\
curso & 11 & gente & 22 \\
paciente & 10 & paciente & 17 \\
conseguir & 8 & colocar & 17 \\
empático & 7 & situação & 17 \\
importante & 7 & falar & 16 \\
falar & 6 & acontecer & 16 \\
medicina & 6 & ficar & 16 \\
sentir & 6 & questão & 15 \\
\hline
\end{tabular}


Vol. 7 | Investigação Qualitativa em Educação: Avanços e Desafios

\begin{tabular}{cccc}
\hline Termo no Ano 01 & Frequência & Termo no Ano 02 & Frequência \\
\hline estudante & 6 & mesmo & 15 \\
tratar & 6 & forma & 15 \\
relação & 5 & concordar & 14 \\
estressante & 5 & casa & 13 \\
começar & 5 & relação & 12 \\
lugar & 5 & conseguir & 12 \\
precisar & 5 & lugar & 12 \\
colocar & 5 & passar & 12 \\
vir & 5 & entender & 12
\end{tabular}

Em relação ao GF feminino que cursou o $1^{\circ}$ Período em 2019 e o $3^{\circ}$ Período em 2020, o somatório de frequências do ano 01 foi de 132 e no ano 02 o somatório das ocorrências foi de 302. O número de ocorrências torna-se mais comparável nesse grupo a partir do sexto termo da análise lexicográfica do Ano 02 (casa, com frequência de 17), sendo proporcional ao primeiro termo da análise lexicográfica do Ano 01 (achar, também com frequência de 17 ocorrências).

Tabela 2. Frequência dos termos mais mencionados pelo Grupo Focal Feminino do $1^{\circ}$ Período em 2019 e do $3^{\circ}$ Período da mesma turma em 2020

\begin{tabular}{cccc}
\hline Termo no Ano 01 & Frequência & Termo no Ano 02 & Frequência \\
\hline achar & 17 & achar & 45 \\
paciente & 15 & número & 22 \\
médico & 12 & ficar & 21 \\
empático & 10 & falar & 19 \\
empatia & 9 & empático & 18 \\
professor & 8 & casa & 17 \\
passar & 6 & comer & 17 \\
tratamento & 6 & gente & 17 \\
exemplo & 5 & vez & 16 \\
maior & 5 & concordar & 14 \\
sentir & 5 & empatia & 13 \\
colocar & 5 & dia & 12 \\
entender & 5 & sentir & 10 \\
vez & 5 & coisa & 9 \\
relação & 4 & passar & 9 \\
momento & 4 & ensinar & 9 \\
conseguir & 4 & entender & 9 \\
lugar & 4 & querer & 9 \\
importante & 4 & mundo & 8 \\
dever & 4 & paciente & \\
& 4 & & 9 \\
\hline
\end{tabular}

Também foram estudadas as análises lexicográficas dos dois GF, masculino e feminino, obtidos com os alunos que cursaram o $2^{\circ}$ período em 2019 e o $4^{\circ}$ período em 2020. 
Dessa forma, pode-se observar na Tabela 3, que neste grupo feminino, a discussão do ano 01 gerou 426 repetições e foram estudados 242 repetições no ano 02 . No quesito frequência, observa-se que os valores entre os resultados das duas coletas tornam-se mais próximos a partir do quinto termo do ano 01 (empatia, com frequência de 30 repetições), sendo proporcional ao primeiro termo do ano 02 (gente, com frequência de 28 repetições).

Tabela 3. Frequência dos termos mais mencionados pelo Grupo Focal Feminino do $2^{\circ}$ Período em 2019 e do $4^{\circ}$ Período da mesma turma em 2020

\begin{tabular}{cccc}
\hline Termo no Ano 01 & Frequência & Termo no Ano 02 & Frequência \\
\hline estar & 51 & gente & 28 \\
achar & 40 & empatia & 21 \\
gente & 40 & achar & 21 \\
médico & 37 & empático & 17 \\
empatia & 30 & passar & 15 \\
empático & 23 & situação & 15 \\
paciente & 21 & acreditar & 13 \\
só & 21 & perceber & 12 \\
ficar & 18 & momento & 11 \\
falar & 15 & coisa & 10 \\
olhar & 15 & mundo & 10 \\
perguntar & 15 & viver & 9 \\
difícil & 14 & colocar & 9 \\
passar & 13 & entender & 8 \\
lugar & 13 & dia & 8 \\
vez & 13 & começar & 7 \\
coisa & 12 & vida & 7 \\
acontecer & 12 & lugar & 7 \\
entender & 12 & importante & 7 \\
problema & & vez & 7 \\
\hline & & & 7 \\
\hline
\end{tabular}

Já na Tabela 4, pode-se observar que neste grupo masculino, a transcrição do ano 01 obteve 323 ocorrências, entre os 20 termos mais frequentes, e foram estudadas 385 ocorrências no ano 02 . No quesito frequência, nota-se que o número de ocorrências se torna mais comparável a partir do terceiro termo do ano 02 (gente, com frequência de 36 repetições), sendo proporcional ao primeiro termo do ano 01 (empatia, com frequência de 38 repetições).

Tabela 4. Frequência dos termos mais mencionados pelo Grupo Focal Masculino do $2^{\circ}$ Período em 2019 e do $4^{\circ}$ Período da mesma turma em 2020

\begin{tabular}{cccc}
\hline Termo no Ano 01 & Frequência & Termo no Ano 02 & Frequência \\
\hline empatia & 38 & estar & 57 \\
achar & 25 & achar & 41 \\
médico & 22 & gente & 36 \\
gente & 22 & empático & 30 \\
empático & 19 & vez & 21
\end{tabular}


Vol. 7 | Investigação Qualitativa em Educação: Avanços e Desafios

\begin{tabular}{cccc}
\hline Termo no Ano 01 & Frequência & Termo no Ano 02 & Frequência \\
\hline acabar & 16 & tentar & 19 \\
paciente & 15 & empatia & 18 \\
mesmo & 15 & médico & 17 \\
falar & 14 & cosa & 15 \\
entender & 14 & paciente & 15 \\
coisa & 13 & conseguir & 15 \\
conseguir & 13 & mesmo & 13 \\
forma & 13 & só & 13 \\
contato & 13 & problema & 12 \\
colocar & 13 & faculdade & 12 \\
querer & 13 & acabar & 11 \\
ajudar & 12 & sentir & 10 \\
passar & 11 & social & 10 \\
lugar & 11 & melhor & 10 \\
dia & 11 & querer & 10
\end{tabular}

\subsection{Análise de Similitude}

Esse tipo de análise é baseado na teoria dos grafos e é usada mais comumente para análises de representações sociais. A Análise de Similitude identifica coocorrências entre palavras e a conexão entre elas, de modo a auxiliar na compreensão do conteúdo do corpus textual. A partir de funções como a "comunidade" e o "halo", que auxiliam na representação gráfica da similitude com cores diversas e agrupamento de palavras conectadas em "zonas", torna-se mais fácil observar de onde flui a discussão e quais termos fazem parte de zonas de discussão distintas (Loubère \& Ratinaud, 2014).

As figuras 1 e 2 representam as Análises de Similitude do grupo focal masculino que cursava o $1^{\circ}$ Período em 2019 e o $3^{\circ}$ Período em 2020. Assim, pode-se ver na Figura 1 quatro comunidades com apenas uma intersecção, entre o núcleo centrado em empatia e o centrado em achar, e representações lineares das discussões na Árvore Máxima, que é o nome dado a essa estrutura da análise de similitude. Já a Figura 2, referente ao mesmo GF masculino que em 2020 cursou o $3^{\circ}$ Período da graduação em medicina, observa-se 11 comunidades com 17 intersecções, apresentando também disseminações na árvore máxima e comunidades secundárias derivadas de outras comunidades. Nessa análise de similitude, torna-se menos óbvio o núcleo da discussão, de modo que pode ser tanto o termo achar quanto o termo empatia. 
Vol. 7 | Investigação Qualitativa em Educação: Avanços e Desafios

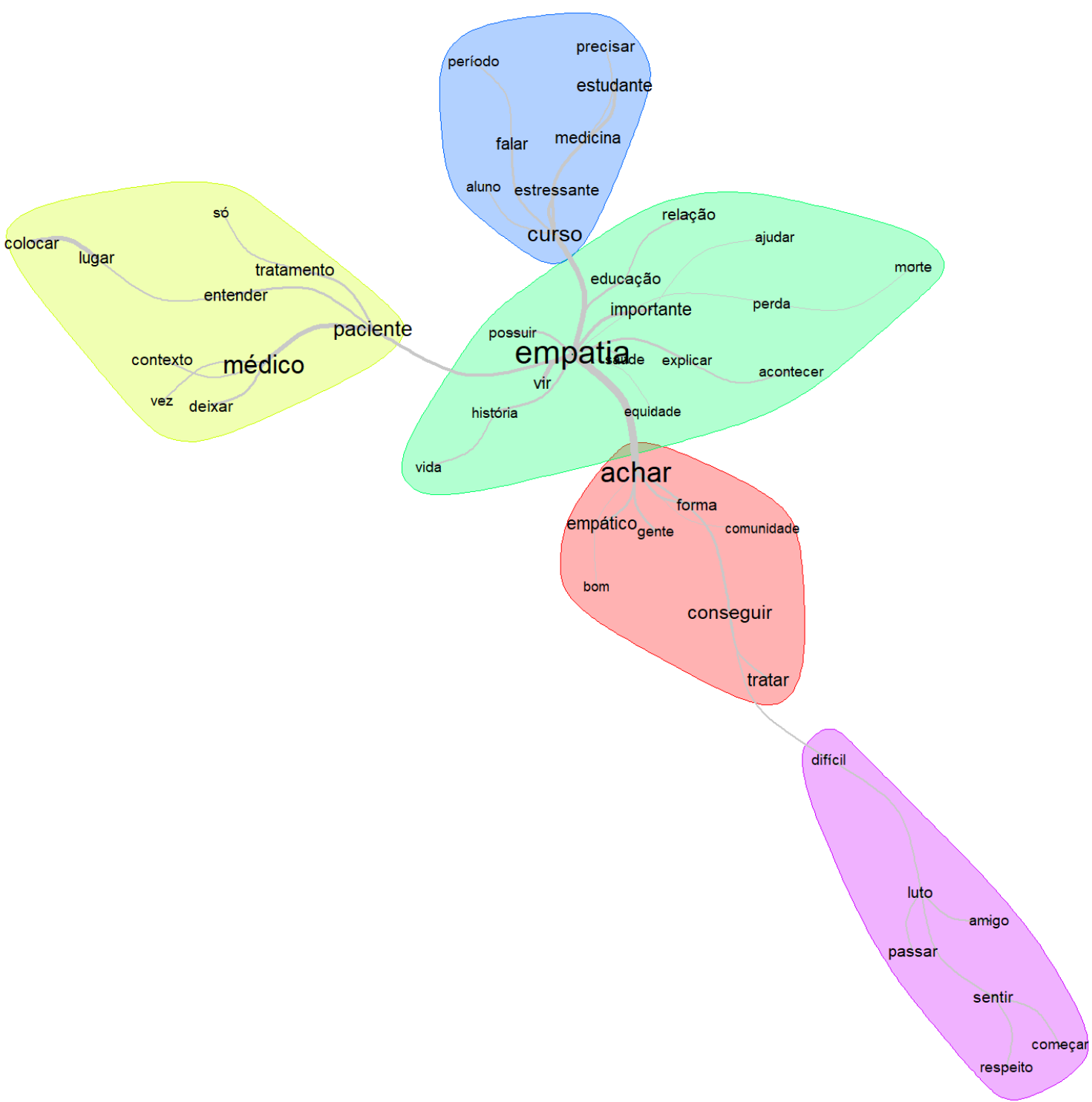

Fig. 1. Análise de Similitude do Grupo Focal masculino do $1^{\circ}$ Período em 2019 
Vol. 7 | Investigação Qualitativa em Educação: Avanços e Desafios

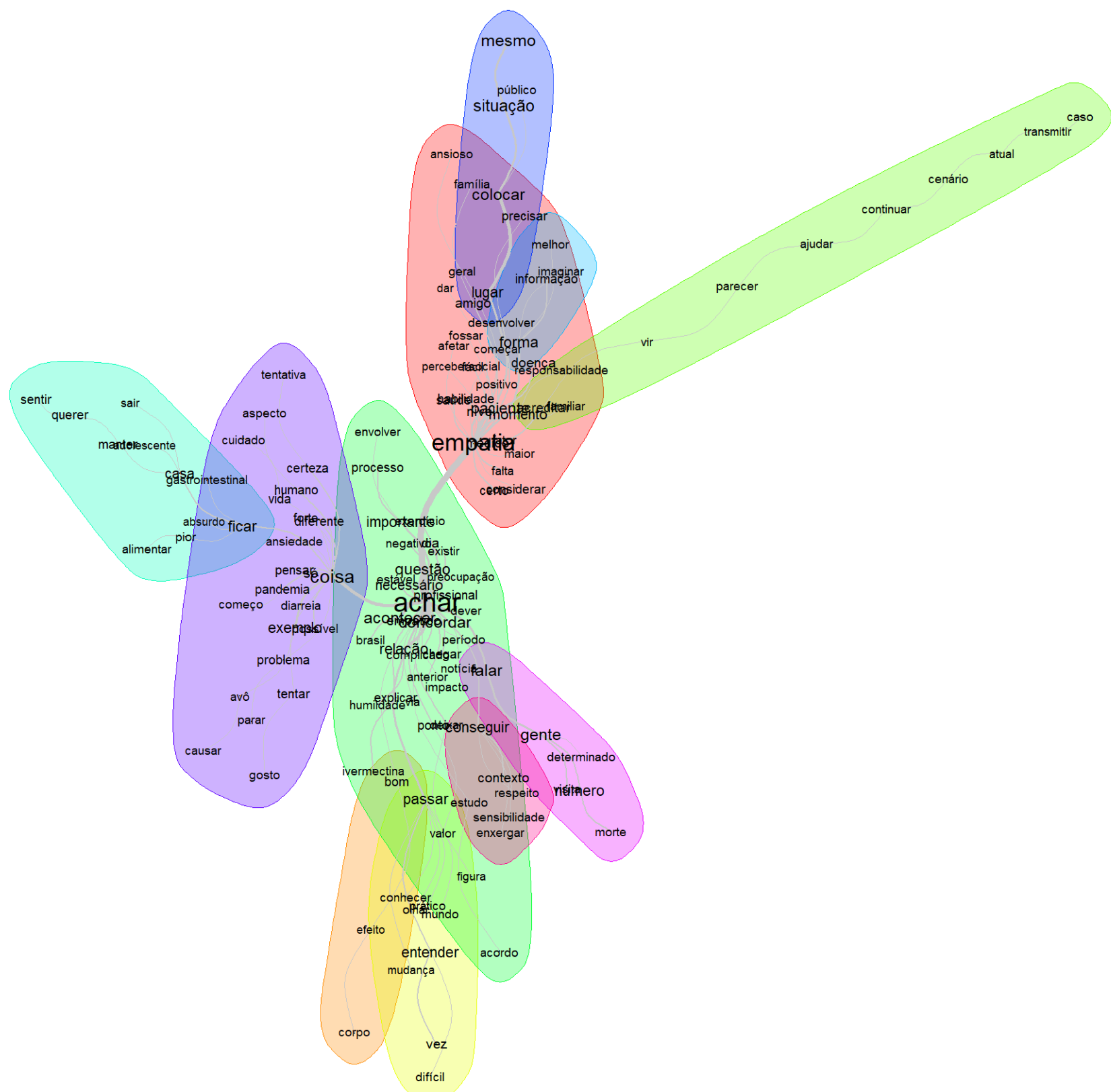

Fig. 2. Análise de Similitude do Grupo Focal masculino do $3^{\circ}$ Período em 2020 
Vol. 7 | Investigação Qualitativa em Educação: Avanços e Desafios

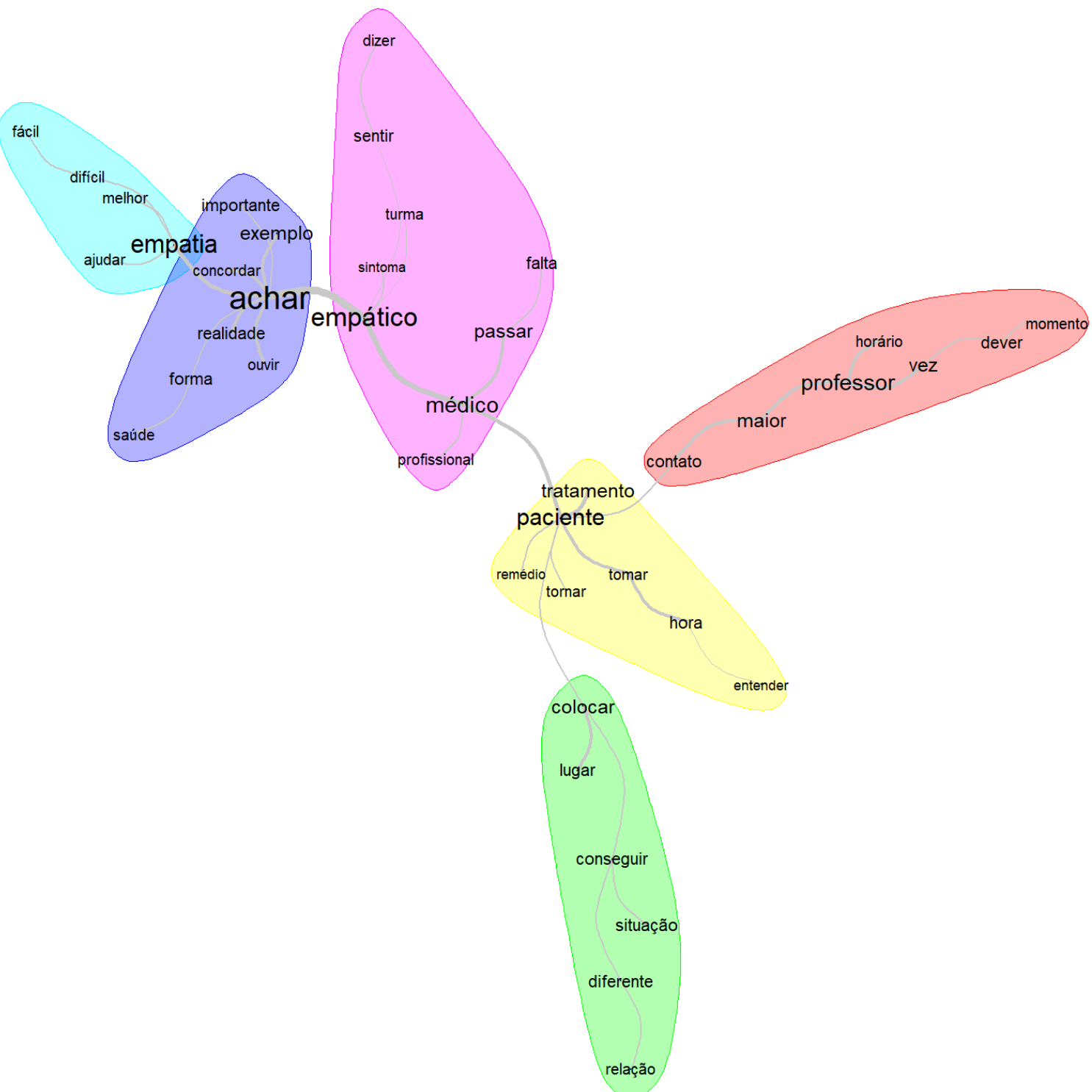

Fig. 3. Análise de Similitude do Grupo Focal feminino do $1^{\circ}$ Período em 2019

As figuras 3 e 4 representam as Análises de Similitude do grupo focal feminino que cursava o $1^{\circ}$ Período em 2019 e o $3^{\circ}$ Período em 2020. Assim, pode-se ver na Figura 3 seis comunidades com apenas uma intersecção, em uma disposição quase idêntica à Figura 1. Já a Figura 4, referente a este mesmo grupo focal, agora durante o ano de 2020, observa-se 10 comunidades com 16 áreas de intersecção, mas sem núcleos secundários gerando ramos na árvore máxima. O Núcleo da discussão permanece único, antes sob o termo paciente e agora sob o termo achar. 
Vol. 7 | Investigação Qualitativa em Educação: Avanços e Desafios

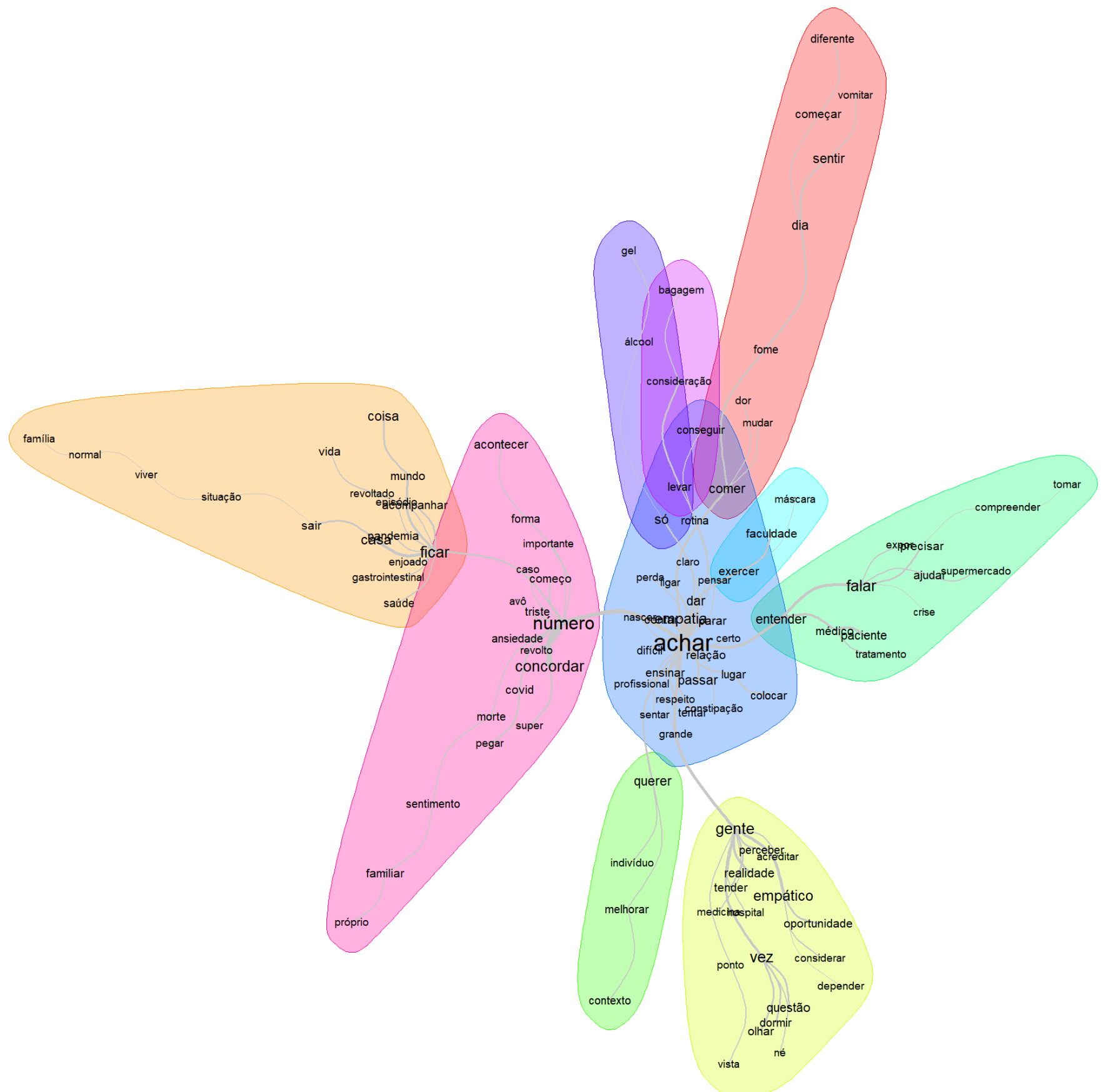

Fig. 4. Análise de Similitude do Grupo Focal feminino do 3 Período em 2020

\subsection{Grupo Focal}

A Nuvem de Palavras é uma organização mais simplificada em relação à Análise de Similitude, mas não menos importante. Ela organiza os vocábulos de maior frequência centralizados e de maior tamanho, enquanto os de menor frequência ficam na periferia da nuvem e com menor tamanho. É um método mais agradável visualmente e de fácil análise dos termos, quando comparada à ferramenta anterior (Camargo \& Justo, 2018). 
Na Figura 5, pode-se observar as Nuvens de Palavras do grupo focal feminino que cursou o $1^{\circ}$ Período em 2019 e o $3^{\circ}$ Período em 2020. Na Figura 5A, pode-se ver que a Nuvem produziu uma imagem de palavras com frequências semelhantes, o que pode ser observado pelo tamanho e disposição dos termos. Na Figura 5B, podemos observar maior variedade de termos e tamanhos de termos, bem como maior amplitude de frequências destes, o que é observado por uma Nuvem de Palavras maior, com termos maiores, médios e menores em uma variação de tamanho mais óbvia.

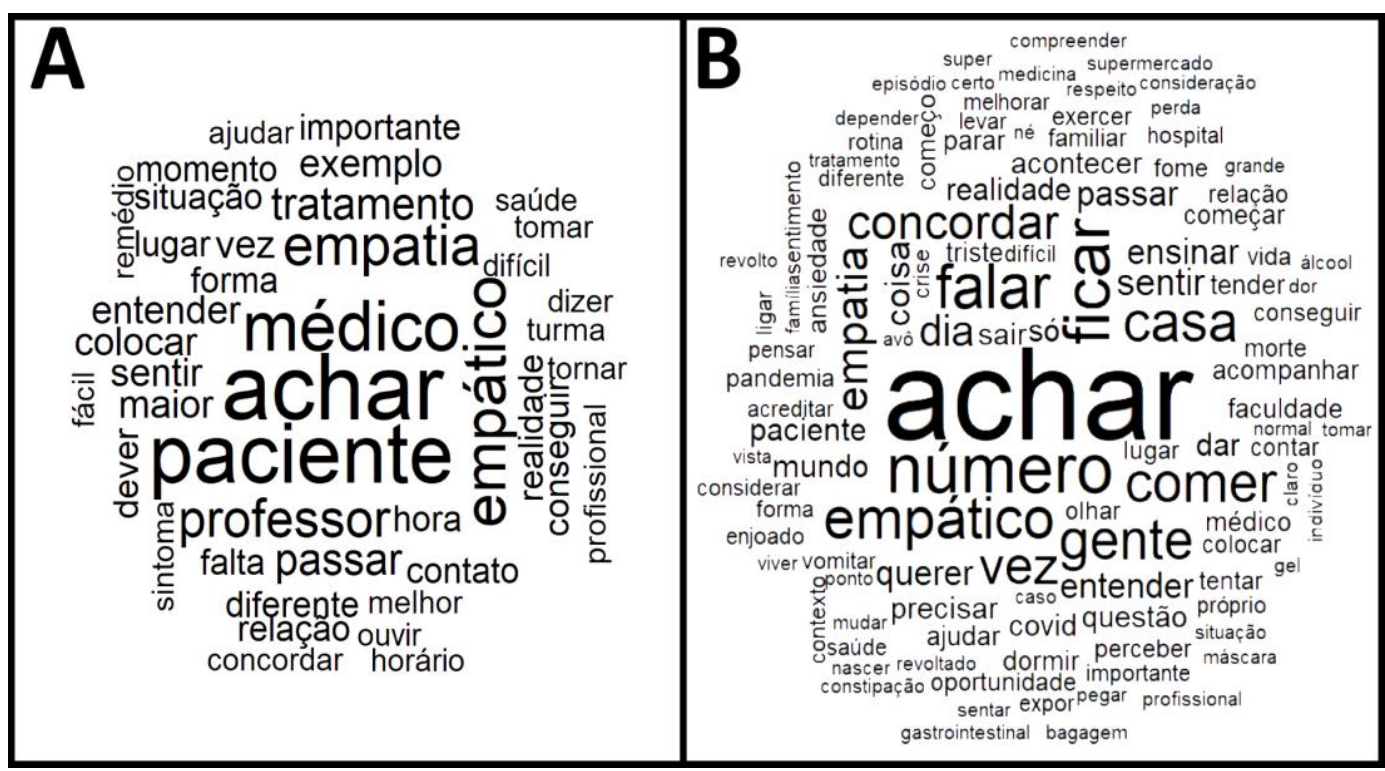

Fig. 5. Nuvens de Palavras do Grupo Focal feminino que cursou o $1^{\circ}$ Período em $2019(5 A)$ e o $3^{\circ}$ Período em 2020 5B)

$\mathrm{Na}$ Figura 6, pode-se ver as Nuvens de Palavras do grupo focal masculino que cursou o $1^{\circ}$ Período em 2019 e o $3^{\circ}$ Período em 2020. Na Figura 6A, pode-se notar que a Nuvem produziu uma imagem similar à Figura $5 \mathrm{~A}$, tanto em tamanho quanto em disposição das palavras. Na Figura 6B, podemos observar uma evolução da Nuvem de Palavras, com maior variedade e tamanhos dos vocábulos, bem como maior amplitude na frequência destes, o que é visto através de uma Nuvem mais complexas, com termos mais variantes em suas disposições e tamanhos. A diferença entre o par de Nuvens deste Grupo Focal masculino para o Feminino da mesma turma é que, enquanto no Grupo Feminino a palavra central da Nuvem permaneceu a mesma, na discussão do grupo masculino houve inversão entre as posições da palavra "achar" e "empatia", com a segunda iniciando com o primeiro lugar em maior frequência e tornando-se a segunda mais frequente um ano depois. 


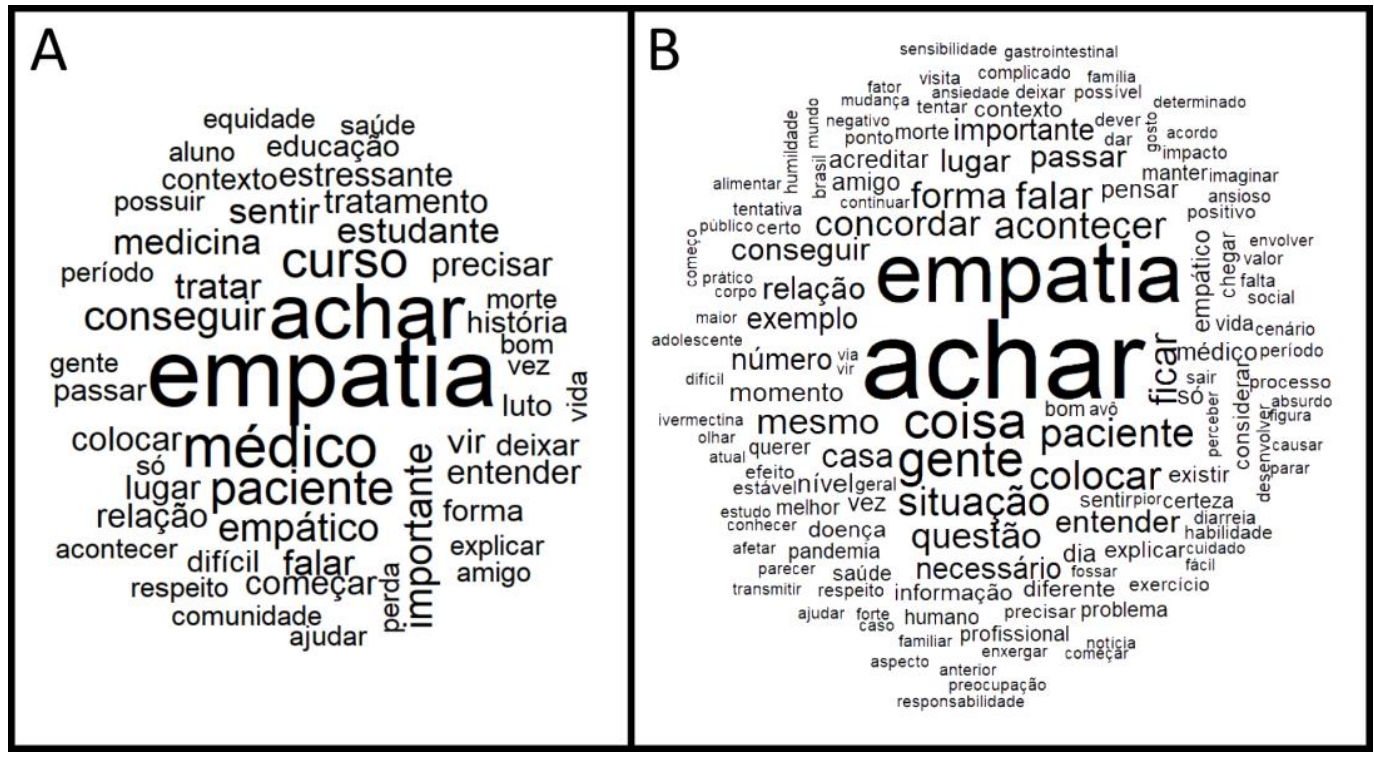

Fig. 6. Nuvens de Palavras do Grupo Focal masculino que cursou o $1^{\circ}$ Período em 2019 (4A) e o 3 Período em 2020 (4B)

\section{Discussão}

Analisando e comparando os dados obtidos em cada recurso no ano 01 e no ano 02 é possível gerar uma discussão acerca desses resultados. Nesse sentido, começando com o GF do sexo masculino que iniciou o $1^{\circ}$ Período em 2019, nota-se tanto na sua nuvem de palavras (Figura 6A), tanto na análise de similitude (Figura 1) que eles concentraram suas falas na roda de conversa no que eles achavam sobre empatia médica, relação médico-paciente e outros termos norteadores. Esse resultado é muito coerente com a situação na qual eles se encontravam, pois, eram estudantes recém ingressados na graduação de Medicina, então, eles naturalmente possuem mais hipóteses sobre esses temas do que experiências concretas. Paralelo a isso, por avaliação comparativa do observador desse GF, foi possível perceber um grupo mais tímido e introspectivo em relação aos demais e ao próprio no ano anterior. Assim, esse fato se faz relevante, uma vez que foi percebido que a conversa tomava o rumo das falas de alguns membros do grupo que eram mais extrovertidos. Dessa forma, a função do observador do GF é muito importante, pois, consegue visualizar as nuances que a roda de conversa tomou e comparar com os dados obtidos processados posteriormente da mesma. Finalizando que apenas a visualização dos dados quantitativos da lexicografia clássica (Tabela 1) não são suficientemente conclusivas em uma pesquisa qualitativa mais complexa.

Trazendo agora o GF feminino que iniciou o $1^{\circ}$ Período em 2019, é notável que há muitas semelhanças com os resultados obtidos no GF masculino da mesma turma, que já foram supracitados. No entanto, é observável que embora a nuvem de palavras seja mais concisa (Figura 5A), ela possui termos mais frequentes como "médico", "paciente" e o ser "empático". Além disso, a similitude entre as palavras mostrou que a conversa foi pautada em menos termos que a do masculino do mesmo ano, mas foi muito mais lógica do ponto de vista organizacional (Figura 3). Sob a luz empírica dos pesquisadores (observador e moderador) neste GF, foi constatado que a conversa foi muito engajada entre todos participantes do sexo feminino, os integrantes sempre complementavam as falas uns dos outros. Ademais, o clima geral foi muito amigável e receptivo, tendo até alguns momentos nos quais os participantes estavam emocionados. Sendo assim, essas visões complementares entre as observações subjetivas em um GF junto com as métricas processadas desses diálogos são de grande valia para a interpretação de cada resultado obtido. 
Entrando agora no segundo ano desta pesquisa longitudinal, a pandemia no novo Coronavírus em 2020 trouxe consigo o isolamento social como principal medida de contenção da propagação do vírus. Nesse sentido, todos os segmentos sociais sofreram adaptações para continuar suas atividades de modo virtual e na universidade não foi diferente. Nesse momento, houve rapidamente mudanças bruscas nas atividades diárias, diminuição da interação humana física e um cenário caótico social com número crescente de mortes, sendo tais alterações muito importantes não somente no concreto, mas também na esfera subjetiva de cada indivíduo. Sendo assim, foi observado na literatura um respaldo científico para a realização de GF na modalidade virtual e assim foi feito para dar continuidade à pesquisa.

Prosseguindo no segundo ano da pesquisa, de modo virtual, o GF do sexo masculino que em 2020 cursava o $3^{\circ}$ Período aderiu bem ao novo formato de roda de conversa. Nela, obviamente, o tema pandemia apareceu entre os termos abordados, visto que todos encontravam-se sensibilizados de alguma forma a respeito disso. E, fazendo um comparativo da similitude gerada no ano 02, com a anterior, do mesmo grupo, é perceptível que os diálogos dessa segunda etapa foram mais robustos, tanto em número de termos, como em correlação entre eles (Figura 2). Desse modo, sobre o conteúdo abordado, o verbo "achar" continua sendo o termo mais frequente podendo ser constatado em todos os recursos de dados processados, como na análise lexográfica clássica (Tabela 1), no tamanho da palavra na nuvem (Figura 6B) e no tamanho da rede dependente do termo na similitude (Figura 2). Entretanto, isso não significa que não houve mudanças significativas nas análises dos discursos entre o ano 01 e 02 . Pois, como já foi citado, a análise completa é feita com a junção dos métodos quantitativos com os qualitativos. Assim, a função de observador em um GF é de suma importância no processo de elaboração de resultados mais fidedignos em uma pesquisa como essa. Porém, essa função fica um pouco comprometida no GF online, visto que se os participantes não quiserem ou puderem ligar suas câmeras, a observação ficará pobre apenas retida ao uso de símbolos do chat, participação no diálogo, alterações vocais e de humor, expressões e relação entre os integrantes. Nesse sentido, os pesquisadores ficaram surpresos com tamanha adesão que este grupo teve em aderir a câmera ligada durante todo o encontro. Apenas um participante não pode ligar, mas participou ativamente de todos os tópicos tratados. Sendo assim, a função de observação de GF não foi comprometida no modo virtual, neste caso.

Dando continuidade para o ano 02 do GF do sexo feminino, que em 2020 cursava o $3^{\circ}$ Período, assim como o GF do sexo masculino do mesmo ano, teve termos no diálogo referentes à pandemia. Dessa forma, o termo "número" ficou em evidência tanto na tabela de frequência (Tabela 2) quanto na nuvem (Figura 5B) e similitude (Figura 4), pois, falaram muito sobre o quantitativo de mortes por COVID 19. Além disso, também conforme a Tabela 2 a frequência do termo "achar" praticamente triplicou de frequência entre no ano 01 e 02 e isso pode estar associado com um maior grau de sensibilização por conta da pandemia. Nesse sentido, além desses dados passíveis de observação concreta, a análise subjetiva do observador desse GF não foi plena. Pois, mesmo todos integrantes tendo participado, apenas metade ligaram as câmeras durante toda discussão. Assim, a visualização completa do diálogo em um âmbito mais humano ficou comprometida, nesta modalidade virtual. Entretanto, o ato por si só não deixa de ser uma ação concreta. Logo, a escolha de não ligar as câmeras, pode significar algum grau de distanciamento entre os integrantes do grupo. Tal constatação é importante na pesquisa longitudinal, porém, não é possível tirar uma conclusão acerca disso, nesta etapa.

A turma que iniciou o $2^{\circ}$ Período em 2019 e que cursava o $4^{\circ}$ Período em 2020, teve resultados semelhantes com a turma discutida anteriormente, com acréscimo das frequências de termos e expansão da discussão no Ano 02 da pesquisa, se comparado ao Ano 01, excetuando o Grupo Focal Feminino, que teve decrescimento das frequências de palavras. É possível perceber que conforme os dados lexicográficos dessa turma, os GF do sexo feminino (Tabela 3) apresentou decréscimo na repetição do termo "empático" e "empatia", todavia, o impacto disso só será visto ao final desta pesquisa longitudinal. 
O Grupo Focal Masculino que iniciou o $2^{\circ}$ Período em 2019 e que cursava o $4^{\circ}$ Período em 2020, no entanto, alcançou um patamar similar aos Grupos Focais de ambos os sexos que iniciaram o $1^{\circ}$ Período durante 2019 (Tabela 4). Nesse sentido, é necessário ressaltar que, nesta turma em questão, os grupos focais de ambos os sexos tiveram mais convites para participação do GF que os da turma que iniciou o $1^{\circ}$ período em 2019 , pois a adesão estava baixa. Durante as discussões virtuais, poucos ligaram as câmeras em ambos grupos e foi percebido de uma forma sútil uma redução das interações globais no grupo feminino, comparado com a experiência do mesmo grupo no ano anterior. Sendo assim, é de suma importância o prosseguimento dessa pesquisa de forma quati-quantitativa para uma melhor discussão e elucidação dos resultados obtidos.

Por fim, ao comparar as duas modalidades de GF em sua praticidade e grau de relevância, foi consenso entre a equipe de pesquisadores que a metodologia virtual é mais prática que a presencial, devido à possibilidade de gravação tanto de áudio quanto de vídeo dos participantes, permitindo uma análise mais acurada do que realmente cada indivíduo, contanto que esteja com a câmera ligada, quis dizer. Entretanto, quando a webcam está desligada as percepções qualitativas e ambientais que circundam esse diálogo são perdidas, conforme Bittencourt (2021), comprometendo o engajamento dos estudantes durante a roda de conversa, podendo, assim, ser um dos possíveis motivos para uma diminuição do rendimento de um dos GF femininos (Tabela 3).

\section{Conclusões}

Os GFs fazem parte um segmento de metodologia qualitativa muito válida e podem trazer muitos resultados palpáveis quando associados com técnicas de processamento do diálogo com a finalidade de quantificação e visualização de diálogos. No entanto, a função de um observador durante a realização destes GF é de suma importância, visto que a conduta implícita dos participantes tem íntima relação com o jeito e a forma com os quais participam de uma roda de conversa. Assim, com esse conhecimento, é gerado, ao final, dados muito mais relevantes para a literatura científica.

No entanto, o mundo tem mudado rapidamente e pesquisas feitas no modo virtual precisam ser estudadas e comparadas para que o mínimo de perdas seja ocorrido. Desse modo, é conclusivo que o uso de GF virtuais é totalmente exequível e bastante prático tanto para os pesquisadores, quanto para os participantes. Porém, a qualidade do resultado está associada com a simulação mais verossímil possível com a de um GF presencial. Logo, é imprescindível que junto com os convites de participação tenha uma sensibilização para que as câmeras estejam ligadas. Não seria um tipo de coerção, visto que, assim como a participação, esse é um ato voluntário. Contudo, a sua ação tem muita importância prática.

\section{Referências}

BITTENCOURT, Renato Nunes. Ensino Remoto e extenuação docente. Revista Espaço Acadêmico, v. 20, n. 227, p. 165-175, 2021.

Camargo BV \& Justo AM (2018). Tutorial de uso do Software IRAMUTEQ, Recuperado em 03 março de 2021, de http://www.iramuteq.org

Dall'Agnol CM, Magalhães AMM de, Mano GC de M, Olschowsky A, Silva FP da. A noção de tarefa nos grupos focais. Revista Gaúcha de Enfermagem. 2012;33(1):186-90.

Gatti AL, Witter C, Gil CA, Vitorino S dos S. Pesquisa qualitativa: grupo focal e intervenções psicológicas com idosos. Psicologia: ciência e profissão. 2015;35(1):20-39.

Loubère L. \& Ratinaud P. (2014). Documentation IraMuTeQ 0.6 alpha 3 - version 0.1 [Computer software]. Recuperado em 19 fevereiro de 2014, de http://www.iramuteq.org

Martínez MG, González LS. Contribución de la técnica del grupo focal al acercamiento a la percepción estudiantil sobre accesibilidad en el entorno universitario. Revista Actualidades Investigativas en Educación. 2015;15(1):1-16. 
Nóbrega DO, Andrade E dos RG, Melo ES do N. Pesquisa com grupo focal: contribuições ao estudo das representações sociais. Psicologia \& Sociedade. 2016;28(3):433-41.

Prates LA, Ceccon FG, Alves CN, Wilhelm LA, Demori CC, Silva SC da, et al. A utilização da técnica de grupo focal: um estudo com mulheres quilombolas. Cadernos de Saúde Pública. 2015;31:2483-92.

Souza MAR, Wall ML, Thuler ACMC, Lowen IMV, \& Peres AM (2018). O uso do software IRAMUTEQ na análise de dados em pesquisas qualitativas. Revista da Escola de Enfermagem da USP, 52(03353).

Woodyatt CR, Finneran CA, Stephenson R. In-person versus online focus group discussions: A comparative analysis of data quality. Qualitative health research. 2016;26(6):741-9. 